BULLETIN Bulletin hispanique

HISPANIQUE Université Michel de Montaigne Bordeaux

117-1 | 2015

Les poètes des rhéteurs

\title{
Manuel Alvar Ezquerra, Las nomenclaturas del español (siglos XV-XIX)
}

Liceus, Madrid, 2013

\section{Luis Pablo Núñez}

\section{(2) OpenEdition}

\section{Journals}

Edición electrónica

URL: https://journals.openedition.org/bulletinhispanique/3930

DOI: 10.4000/bulletinhispanique.3930

ISSN: 1775-3821

\section{Editor}

Presses universitaires de Bordeaux

\section{Edición impresa}

Fecha de publicación: 1 junio 2015

Paginación: 375-378

ISBN: 979-10-300-0174-7

ISSN: 0007-4640

\section{Referencia electrónica}

Luis Pablo Núñez, «Manuel Alvar Ezquerra, Las nomenclaturas del español (siglos XV-XIX)», Bulletin hispanique [En línea], 117-1 | 2015, Publicado el 01 septiembre 2015, consultado el 12 febrero 2022. URL: http://journals.openedition.org/bulletinhispanique/3930 ; DOI: https://doi.org/10.4000/ bulletinhispanique.3930

Este documento fue generado automáticamente el 12 febrero 2022

Tous droits réservés 


\title{
Manuel Alvar Ezquerra, Las nomenclaturas del español (siglos XV- XIX)
}

Liceus, Madrid, 2013

\author{
Luis Pablo Núñez
}

\section{REFERENCIA}

Manuel Alvar Ezquerra, Las nomenclaturas del español (siglos XV-XIX). Madrid, Liceus, 2013, 721 p. (Estudios. Lengua española). ISBN 978-84-9714-042-3. $50 €$

Desde hace ya varias décadas el profesor complutense Manuel Alvar Ezquerra lleva dedicando numerosas páginas a la elaboración e historia de los diccionarios. Ejemplos destacados de ello son el Nuevo tesoro lexicográfico del español (s. XIV-1726), coordinado junto con Lidio Nieto (Madrid, Arco Libros, 2007), o su más reciente proyecto Biblioteca Virtual de la Filología Española (BVFE, anteriormente en el servidor de la Universidad Complutense, pero ahora accesible desde la página electrónica <http://www.bvfe.es/>), así como también los numerosos libros y artículos publicados desde hace más de treinta años. Este voluminoso libro, que es una parte desgajada de la historia de la lexicografía española que está proyectando (y que quizá en años futuros vea la luz), se dedica específicamente a las nomenclaturas, repertorios léxicos donde las voces se agrupan temática o conceptualmente, y más en concreto a las publicadas entre los años 1493 y 1899.

Es innecesario decir que un estudio tan amplio, que abarca un periodo de prácticamente cinco siglos, es un esfuerzo ímprobo, y muestra de ello son las más de setecientas páginas de que consta esta obra o los más de 150 títulos analizados. El esfuerzo es además especialmente destacable en lo que se refiere al siglo XIX, pues, si de los siglos anteriores (XV-XVIII), más estudiados por otros investigadores, señala 71 obras, solo del XIX estudia 81. Esto es especialmente importante, porque el XIX sigue 
siendo el gran cajón de sastre de los estudios historiográficos actuales. Pero no nos engañemos: como señala el autor, «no se trata de un catálogo bibliográfico, sino de una enumeración de las nomenclaturas» (p. 16) analizadas sintéticamente. Que sea tan gran número de títulos se explica por la finalidad de la obra: ofrecer una visión panorámica, lo más completa posible, de las nomenclaturas del español, poniendo «un poco de orden» (p. 17).

3 La versión publicada se corresponde con las investigaciones terminadas en octubre de 2012 (p. 17), pero, junto a capítulos escritos específicamente para esta historia de las nomenclaturas, se sintetizan en ocasiones otros realizados previamente sobre algunos títulos concretos (como por ejemplo los relativos a la Janua linguarum de Bathe o a las nomenclaturas de Pedro de Arenas, Alejandro de Luna o Lorenzo de Robles, donde resume el capítulo publicado en el Homenaje a Ramón Trujillo de 1999, etc.). En gran parte es lógico: no hay que desestimar los trabajos que el mismo autor realizó sobre esas obras de forma pionera hace años, y tampoco un estudio panorámico de este tipo puede prescindir de los trabajos realizados por otros investigadores (muchos de ellos discípulos). Esto explica que sean citados con frecuencia artículos de Marta C. Ayala Castro, María de los Ángeles García Aranda (autora de una tesis dirigida por el propio Alvar Ezquerra sobre nomenclaturas hispanolatinas desde 1493 a 1745) o nuestro estudio El arte de las palabras: Diccionarios e imprenta en el Siglo de Oro (2010) donde recogimos un panorama de las nomenclaturas hispano-francesas de los siglos XVI y XVII con una metodología muy similar a la ofrecida por Manuel Alvar en esta obra. Hay que mencionar, no obstante, que, para el estudio de cada nomenclatura, el autor ha manejado ejemplares originales, de la Biblioteca Nacional de España fundamentalmente o de su propia biblioteca particular, o ejemplares digitalizados disponibles a través de bibliotecas virtuales de otras instituciones, por lo que sus observaciones son de primera mano.

4 La estructura del libro se podía describir de la siguiente manera: además de los preliminares y del índice final onomástico, para cada obra se dedica un breve capítulo monográfico que contiene de forma sistemática estos apartados: una somera presentación en varias líneas del autor y la obra (sin considerar los datos biográficos, pues en muchas ocasiones poco o nada se conoce de los autores), la transcripción ocasional de algún párrafo del prólogo o preliminar del original, la estructura de la nomenclatura con la indicación de los epígrafes que la componen, su número aproximado de entradas y la transcripción de algún apartado a modo de muestra del contenido. La extensión de cada capítulo es sin embargo variable, acorde también con la mayor o menor importancia de cada obra: desde las siete $u$ ocho páginas dedicadas a las nomenclaturas de César Oudin, Chantreau o Eugenio de Ochoa, a un breve párrafo, como ocurre con la anónima Guía de la conversación española de 1835 (p. 490) -versión abreviada del Arte de Chantreau- o con Il perfetto dialoghista de 1898 (p.681) reproducción de otra de Corona Bustamante-: si la nomenclatura es plagio de otra, basta con remitir al estudio señalado previamente.

5 La cantidad de autores y obras consideradas es grande y por su diversidad permite trazar la historia de las nomenclaturas con el español. La clasificación seguida en este manual es cronológica, por lo que no hay una distribución de títulos de acuerdo con tipologías, lugares de publicación o lenguas (es decir, no hay un apartado dedicado a las nomenclaturas hispano-italianas y otro a las hispano-francesas, por ejemplo, del mismo modo que no están agrupados los manuales de conversación con respecto a las 
nomenclaturas insertas en gramáticas o diccionarios: se opta por una ordenación de acuerdo con la fecha de su publicación); a pesar de ello, a lo largo de los capítulos se hacen referencias cruzadas para indicar cuándo una obra procede de otra o su contenido es plagio de alguna anterior. En ocasiones también se destaca algún título más relevante que marcó época y sirvió de modelo para otros y, en la introducción, se señala cómo «con el transcurrir del tiempo, el contenido fue cambiando como veremos en este libro» (p. 21), lo que demuestra la voluntad de trazar una historia de las nomenclaturas que supere la descripción monográfica que se hace de cada una. Esto, no obstante, queda a veces algo difuso, y podría haberse hecho un esfuerzo mayor por mostrar esas interrelaciones o dependencias añadiendo algún tipo de gráfico, esquema o tabla recapituladora que mostrara las semejanzas entre varias de las obras analizadas, de manera que fuera visualmente más patente.

En el recorrido histórico de obras encontramos fundamentalmente títulos bilingües con el español y otra lengua europea, otras veces plurilingües, pero es interesante notar que también se recogen nomenclaturas con el árabe o con lenguas del Sudeste asiático (fundamentalmente las nomenclaturas con lenguas filipinas). Esto, en cierta manera, muestra el interés histórico hacia determinadas regiones y lenguas. También se señalan nomenclaturas manuscritas, como la de Miguel Saura (p. 71) o el Diccionario manual de voces ynglesas del siglo XVIII (Ms. 18453 de la BNE, p. 250), entre otros. Sin duda, el panorama es el más completo hasta la fecha y poco queda por añadir en lo referido a la nómina de obras posible, aunque el propio autor no está seguro «de que no haya quedado nada fuera». A este respecto, sí podríamos añadir algunas más que en la obra no se señalan, especialmente varias del siglo XviII que, por haber quedado manuscritas, no son conocidas aún por los investigadores. Una de ellas sería por ejemplo una nomenclatura manuscrita bilingüe de $272 \mathrm{pp}$., fechada en 1774, donde, a doble columna, se agrupan las voces españolas y francesas pertenecientes primero al universo y la naturaleza, luego al hombre, con sus oficios y disciplinas -con un apartado para la óptica, por ejemplo-, hasta llegar a las religiones y las dignidades eclesiásticas, con que concluye: se trata de una obra extensa con un total de 251 apartados. Otras que podrían añadirse a la obra de Alvar Ezquerra serían en cambio esbozos breves, cinco nomenclaturas manuscritas de muy escasa amplitud, pero muy relevantes por ser las primeras en que se pone en paralelo el español con ciertas lenguas amerindias (daremos noticia más detallada de cada una de estas nomenclaturas y de otros vocabularios inéditos en un estudio que estamos terminando). En algún otro caso, la historia de algún título concreto ofrecida por Manuel Alvar Ezquerra podría ampliarse aún más, como en otras ediciones de la Janua de Bathe de finales del siglo xvir y comienzos del xviII que el autor no menciona y no parece conocer. También es probable que en el futuro se conozcan nuevas nomenclaturas no señaladas aquí, especialmente del siglo XIX, surgidas a la luz de los nuevos métodos de enseñanza de idiomas, como Berlitz, Ollendorf, etc. No obstante, como señala el propio Manuel Alvar, su manual pretende ser ante todo una guía panorámica, magnífica, de hecho, sobre cuyos títulos podrán hacerse posteriormente estudios más detallados.

7 Si el siglo xIX supuso un cambio en la agrupación del léxico más moderna y acorde con la realidad social, el siglo xx continuaría lo desarrollado en el anterior sin ningún cambio brusco al respecto. El sistema editorial potenciaría las guías de conversación y guías para viajeros con fines turísticos, haciendo que lo que en otras épocas era un recurso de aprendizaje complementario de obras de diálogos y gramáticas, pase a 
integrarse poco a poco en las unidades de manuales: los métodos basados más en oraciones y frases acabarán desplazando las listas de palabras, que nunca serán del todo eliminadas porque la necesidad de agrupar temáticamente el vocabulario para facilitar su memorización no ha cambiado.

8 Aunque en la obra no se mencione, no debe escapársenos tampoco que las nomenclaturas con el español estudiadas aquí tienen sus paralelos en las publicadas para otras lenguas. Por ejemplo, en Centroeuropa, el editor Karl Baedeker publicaría manuales como el Manuel de conversation pour le touriste, en quatre langues (français, allemand, anglais, italien), avec un vocabulaire, un choix de questions diverses (la 18. ${ }^{a}$ ed. es de 1866, pero la versión inglesa contó con más ediciones, como The Traveller's Manuel of conversation in four languages, English-French-German-Italian with vocabulary, 22nd ed., 1875) donde las primeras 150 páginas son una nomenclatura, y el resto diálogos para diferentes situaciones. Los manuales de conversación plurilingües de Garnier Frères (como el de seis lenguas francés, inglés, alemán, italiano, español y portugués de 1900) dedican más de cien páginas (una cuarta parte) a la nomenclatura, antes de los ejercicios gramaticales, diálogos y modelos de cartas. En Norteamérica habrá obras similares, con nomenclaturas y diálogos, como los Conversational Phrase-Book for the Use of Students and Travellers publicados en Nueva York. Y, ya en el siglo xx y con fines escolares, las nomenclaturas aún seguirán siendo útiles: por ejemplo, en 1949 se imprimió en Berna para los escolares germanohablantes un Vocabulaire systématique Français-Allemand cuyo autor, Pierre Borel, distribuía los contenidos comenzado por el mundo (astronomía, geografía y geología, el hábitat...), siguiendo por el hombre y sus elementos culturales vinculados (vestimenta, alojamiento, familia, condición social, vida privada y cívica, Estado), para acabar con las voces relacionadas con la manera de ser, la vida afectiva e intelectual, la moralidad y la religión (es decir, prácticamente el orden visto ya en 1774). Aunque tampoco hay que irse demasiado lejos ni a otras lenguas: la Editorial Cantábrica de Bilbao publicó en los años setenta del siglo xx una colección de guías de conversación "Yale» bilingües con el español donde se insertan pequeñas nomenclaturas en los apartados de frases usuales, al mismo tiempo que se añaden nociones gramaticales de la lengua al inicio y un breve diccionario bidireccional al final: el espíritu de aquellas obras de siglos anteriores sigue pues vigente, tanto en su contenido como en su pequeño formato de bolsillo, y un manual como el que ha realizado Manuel Alvar Ezquerra nos ayuda a conocer su historia, su amplia difusión y su vigencia, pues, ya sea en un formato impreso o digital, la agrupación didáctica del vocabulario de una lengua continuará siendo precisa.

\section{AUTORES}

\section{LUIS PABLO NÚÑEZ}

Consejo Superior de Investigaciones Científicas - Madrid 